\title{
Interbehaviorism Evaluation of Precurrent Repertoires and Reading Comprehension in College Students
}

\author{
Mario Ángel-González¹, Francisco Javier Pedroza-Cabrera ${ }^{2}$, Cecilia Colunga-Rodríguez ${ }^{3,4}$, \\ Mercedes Gabriela Orozco-Solis ${ }^{4}$, María de Lourdes Preciado-Serrano4, María Luisa Ávalos-Latorre5, \\ Julio César Vázquez-Colunga ${ }^{4}$, Claudia Liliana Vázquez-Juárez ${ }^{4}$
}

\author{
${ }^{1}$ University Center of Tonala and University Center for Health Sciences, University of Guadalajara, Guadalajara, Mexico \\ ${ }^{2}$ Autonomous University of Aguascalientes, Aguascalientes, Mexico \\ ${ }^{3}$ Pediatric Hospital of the National West Medical Center at the Instituto Mexicano del Seguro Social (Mexican Social Security Institute, or \\ IMSS), Guadalajara, Mexico \\ ${ }^{4}$ University Center for Health Sciences, University of Guadalajara, Guadalajara, Mexico \\ ${ }^{5}$ University Center of Tonala, University of Guadalajara, Guadalajara, Mexico \\ Email: mario.angel@ensj.edu.mx,francisco_pedroza@hotmail.com
}

How to cite this paper:Ángel-González, M. et al. (2016) Interbehaviorism Evaluation of Precurrent Repertoires and Reading Comprehension in College Students. Creative Education, 7, 2389-2402.

http://dx.doi.org/10.4236/ce.2016.716230

Received: September 8, 2016

Accepted: October 11, 2016

Published: October 14, 2016

Copyright $\odot 2016$ by authors and Scientific Research Publishing Inc. This work is licensed under the Creative Commons Attribution International License (CC BY 4.0).

http://creativecommons.org/licenses/by/4.0/

\begin{abstract}
The aim was to evaluate the precurrent repertoires and reading comprehension levels in college students. An analytical cross-sectional study, based on interbehavioral theory, was designed. The sample included students from six schools, using a stratified sampling technique. The participants answered a writing test that included sociodemographic and academic data, three specific test designed to evaluate precurrent repertoires (word recognition, phrase recognition and use of lexicon) and one test for the evaluation of reading comprehension. Descriptive analysis was applied, along with $\chi^{2}$ to evaluate the associations between the precurrent repertoires and comprehensive reading. The final sample included 147 students. The mean age was 22.5 years (SD 5.3), $70.7 \%$ were female, $85 \%$ single and $53.7 \%$ without paid employment. The results indicated that $56.5 \%$ of the participants obtained a high level in precurrent1 (word recognition); 19\% for the precurrent 2 (phrase recognition), and $12.2 \%$ for the precurrent 3 (Use of lexicon). The reading comprehension level was high for $1.4 \%$ of the participants; $74.8 \%$ average, and $23.8 \%$ low. An association between precurrent 1 and reading comprehension was found. It is concluded that the results in reading comprehension are low and although precurrent results are higher than the reading comprehension levels, only one association is found between them.
\end{abstract}

\section{Keywords}

Precurrent Repertoires, Reading Comprehension, Interbehaviorism 


\section{Introduction}

Reading comprehension is the mainstay for the educative processes at the higher educational levels and for the development of self-learning abilities, therefore, the reading of academic text is one of the pedagogic strategies most used by the teachers at the basic and higher levels, seeking to develop a connection between the students and the disciplinary contents (Arroyo, Canales, Morales, Silva \& Carpio, 2007). The education that a student obtains at the higher levels, more related to scientific and technological training, is consider as a key factor for the development of the country, given that it can influence in the unemployment reversion, the decrease of social exclusion and the dejection of the elements that generate low development indexes (Acuña, Irigoyen, \& Jiménez, 2013), in that matter, several authors point out that in order to maximize the learning processes, during this and other educational levels, the students need to develop an efficient set of reading skills (Acuña et al., 2013; Arroyo, Canales, Morales, Silva, \& Carpio, 2007; Morales-Chávez, Hernández-Reyes, León, Cruz-Alcalá, \& Carpio, 2010; Irigoyen, Acuña, \& Jiménez, 2013).

Notwithstanding the importance of reading comprehension, Irigoyen, Acuña and Jiménez, 2013, concluded through the results found in different research, that the low reading comprehension levels found in the basic school level evaluations persisted all the way thru the higher educational levels. Despite the fact that the educational and governmental authorities acknowledge the important need of develop reading comprehension abilities, and that the Plans and Programs for Basic Education (Secretaría de Educación Pública, 2011a; 2011b) include contents and actions aimed to that purpose, the results from the national and international evaluations suggest that the students of all the educational levels do not read with adequate comprehension levels, given that, according to theses evaluations, the Mexican students have important backlogs that do not allow us to reach the expected levels for a country such as ours (Zarzosa \& Martínez, 2011).

The international evaluations from the Organization for Economic Cooperation and Development (OECD), have found that the Mexican students at the basic educational levels have significantly low levels of reading skills, (OECD, 1999; 2003; 2009; 2011). These deficiencies have been also found in evaluations performed to the first admission students majoring in psychology from two public universities in Mexico, in which it was found that the students from both institutions have deficient reading comprehension abilities, specifically in the graphic reading, the argumentation based in information presented in a text and for the communication of complex ideas (Mares, Hickman, Cabrera, Caballero, \& Sánchez, 2009; Irigoyen, Mares, Jiménez, Rivas, Acuña, Rocha, Noriega, \& Rueda, 2009).

These results are alarming by them self's, but the gain even more relevance when those students, with important deficiencies, start the higher educational levels. Given that at the basic and higher educational levels, it seems to exist the assumption that the simple information provided to the students in educational context will transform in the ability of interact with different functional levels and linguistic modalities, as well as 
the possibilities of pertinent application in daily and non-schooled situations (Irigoyen, Acuña, \& Jiménez, 2013).

\section{Theoretical Framework}

The analysis of reading comprehension from the interbehavioral perspective has its origin in the Kantor's theoretic proposal $(1968,1977)$. The author points out that the language it's a specific form of adjustative behavior, given that the linguistic interactions constitute complex adjustments in situations and circumstances that are specifically human, such as reading a text. Kantor (1977) distinguished two types of linguistic interactions, the referential and the symbolic.

Fuentes and Ribes (2006) point out that reading comprehension its conformed by three moments. In the first part, the writer acts upon the stimuli that he will write about; for example, the writer listen something such as musical piece or contemplate a landscape. In the second moment, the author writes a text about the stimuli upon which he behaves previously. When the author writes the text, he transforms for the reader the contingencies stablished when he interacted with the stimuli previously. The writer substitutes the original contingencies for the potential reader, which allows the text to acts as an auxiliary object of stimuli or as an adjust stimuli object for the potential reader. Finally, the third situation occurs when the reader reads comprehensively the text. In other words, the reader is supposed to interact substitutive thru the text.

These same authors point out that comprehend do not necessary implies the realization of a mechanical or instrumental action, just as it occurs with the term read, although it means that the individual that acts as a competent reader is capable to do some things when its necessary. When a reader comprehends a text, he can do different type of actions upon the pertinent circumstances, given that, being a comprehensive reader means to have the ability or tendency of doing different type of things. The psychological interactions, including the reading comprehension, can occur in five functional levels, mentioned by Ribes and López (1985), the contextual, supplementary and selective, that correspond to situational interactions, meanwhile, at the substitutive level, the referential and non-referential interactions will correspond to extrasituational and transituational interactions, respectively.

According to Fuentes (2007), in reading comprehension, as in any linguistic interaction, the mediation is carry out when the writer and the reader respond conventionally to the object of adjust stimuli. The conventional response, differs from the perceptive response, given that this one its executed situationally upon the stimuli contained in the text even when they can share some particular functional dimensions, because the conventional response allows the reader to deslindate from the situationally of the object of auxiliary stimuli, allowing the reader to behave conventionally upon the stimuli object of adjust stimuli non present and apparent in the interactive situation.

In reading comprehension its essential that the reader interacts with the functional characteristics of the text that regard the stimuli object. We can identify three principal characteristics: 1) the reading behavior must be linguistic; 2) the reading behavior must 
be pertinent to the stimuli object contained in the text; and 3) the reading behavior must be functional regarding the text modality. These characteristics conduct to three repertoires of precurrent abilities that the comprehensive reader must perform to facilitate the text reconstruction reading comprehension.

Fuentes, 2005, defined the first precurrent as the lexicon repertoire, which regards to the vocabulary that constitutes the text. Two skills can be included into this repertoire, the first is to identify the "key" words, understanding its significance in the context that are used, including the identification of isolated key words and key words included in the textual phrases. The second skill is to use the key words, identifying the use of these words in non-literal phrases in the text, but formulated about the same stimuli object.

The second repertoire is the thematic, related to the domain in which its inserted the stimuli object about which the text is written. It corresponds to a specific domain of knowledge. When the individual has a thematic repertoire, he can talk and write about the stimuli object corresponding to the topic, when he reads and listen, he can talk about it, can identify it and relate it with other topics, agreeing or disagreeing with the things that the other persons writes or arguments about. Have a thematic repertoire means that the individual can interact linguistically with the objects or events regarding the topic, transcending its apparent physical characteristics, and independently of its physical presence. The thematic repertoire is a result of the linguistic history of the individual that has specific objects or events.

The third repertoire is the instrumental, which regards to the general and specific skills for each type of text. The delimitation of these actions, performed during comprehensive reading, depends of the conceptualization of reading comprehension. Fuentes and Ribes (2001) consider that comprehensive reading is center in the instrumental skills that correspond to the functional characteristics of the text.

\section{Elements of Reading Comprehension}

In order for the reading to be comprehensive is necessary, but not enough, to read textually, so, read comprehensively, refers to the act in which the reader responds to the conventional properties of the text, as a stimulus that relates to divers objects and natural or linguistic events, and to the behavioral practices related to that. When the reader has a conventional response to the text that mediates the contact with the stimuli object, this conventional behavior allows the reader to untie from the adjust stimuli object non present or apparent to the interactive situation (Ribes \& López, 1985; Ribes, 1990).

When we talk about the text used as study materials, Fuentes (2005) points out that there are three different forms. The first is called behavioral modality, in this form, the writer requires the reader to do something with or about the text. The second form is the constative, in which the reader describes, narrates or mentions objects or extrasituational events. In these types of texts, the writer writes, describes, mentions or shows objects, situations, properties, sequences of events, etc. These texts always have an extra situational pertinence. In the final form, called definitional, the writer introduces symbolic or linguistic interactions that exemplified or require the meeting of normative 
criteria to be understood. The stimuli object of these texts has a transituational pertinence.

\section{Research Setting}

In Mexico, the school system is conformed by three levels: the basic, the high school and the college level, in which this research was developed. According to a national census, by 2012, the country had 2939 public universities and 1955 in the private sector, in these institutions, almost 2.93 million students were enrolled at a national level (Fuentes, 2013). The research was developed in six different institutions of college level from the public sector, located in Guadalajara, Jalisco, Mexico.

\section{Methodology}

\subsection{Participants}

From each participating institution a representative sample of students was selected using a stratified sampling technique. The participants were selected by opportunity, using the inclusion criteria of being regular students in a college institution, accepted to participate voluntarily in the research and to sign the informed consent form. The final sample consisted of 147 college students, from which 23 were enrolled in a master's degree program and 124 in a bachelor's degree program, of this group, 42 students were coursing a Public health program, 15 from medical school and 67 students from education school, of which 20 were enrolled in the preschool level, 18 in the elementary, 16 in the middle school and 18 from the physical education program. The participants that do not answer the test completely and whom once enrolled in the research decided not to keep participating, were excluded.

\subsection{Instruments}

A test was designed by the researchers based in the interbehavioral theory. The test consisted of a text and five sections: a sociodemographic page, three different test to evaluate the precurrent repertoires (word recognition, phrase recognition and use of lexicon) and one for the reading comprehension.

The text was designed from different academic texts, it consisted of 1577 words distribute intro four pages with 12 point Times New Roman font and a 1.5 line spacing. The functional modality of the text was constative, in which objects or extrasituational events are mention, describe or narrate.

The sociodemographic page included demographic and academic data. The first section gathers information about age, gender, marital status and the maximum school level attained by parents. The second section gather data about the college attended by the participant, the school level study currently and the grades obtained in the last evaluation.

The first test for the precurrent repertoires, word recognition, consisted in a two column evaluation: one with 10 key words and the other with 12 definitions, of which 
10 options defined the key words and two functions as distractors. The second test evaluated the phrase recognition, consisting of two columns as well: the first had 12 literal phrases taken from the text and the second with 10 paraphrased phases. The instruction in this test was to relate the 10 literal phrases with its corresponding paraphrased version from the second column. The third test evaluated the precurrent repertoire use of lexicon, consisting of 10 incomplete phrases, non-literal to the text, and a listing of 12 key words at the end of the page, with which the participant needed to complete the phrases. The final test, designed to evaluate the reading comprehension, consisted in an evaluation of extrasituational skills, presenting 15 items in which the participant needed to stablish connections between the text fragments and everyday situations that related to the text content.

For the establishment of the test fiability, a interjudges content validity test was applied, obtaining a Content Validity Index of .89 for the complete test. The fiability was calculated using KuderRicharson test, with a resulting value of 0.70 , considered adequate.

\subsection{Data Collection}

The test implementation was developed in two phases during a single session. In the first phase, the constative text was delivered to the participant, and when they finished reading it, the text was taken away, proceeding to deliver the sociodemographic page and the precurrent repertoires tests, the participant was not allowed to review the text during the answer of these tests. In the second phase, the constative text was delivered again to the participant along with the reading comprehension test, considering that the aim was to evaluate the reading comprehension and not the memory, the participant was allowed to consult the text during the answering of the test.

There was not limit time for the reading of the text and the answer of the tests, however, the average time for answering the tests was 50 minutes. The tests were graded according to the number of correct answers obtained by the participants, in the precurrent repertoires test, the right answers obtained by the participant were categorized into low, average and high levels, meanwhile in the reading comprehension test, the results were categorized in approved and non-approved.

\subsection{Data Analysis}

Once the tests were graded, we proceeded to encode and capture the results into a data base in the SPSS version 20.0 program. Descriptive analysis was performed, using distribution and variability measures, as means, standard deviation and frequencies. The data obtained for the precurrent and reading comprehension tests was categorized into ranges low, medium and high using the total score obtained for the participants. The $\mathrm{z}$-score was calculated, taking as low, the data values lower than minus two standard deviations; as medium, the scores between minus two and plus two standard deviations, and, as high the values over plus two standard deviations. The association between precurrent repertoires and comprehensive reading was analyzed using $\chi^{2}$, taking a value 
of $p<.05$ as significant

\subsection{Ethic Considerations}

As ethical aspects of the research, the participants signed an informed consent form in which was explained that the participation in the study was voluntary, having the option to withdraw from the research at any point without any academic consequences, given that the participation in the study did not had value for the school grades. Also, the form explained the respect for the anonymity of the participants and the confidentiality of the results. Finally, the participants were informed that if anyone would like to know the results obtained in the tests, they could request them to the main researcher.

\section{Results}

\subsection{Sociodemographic and Academic Characteristics}

The mean age of the participants was 22.5 (SD 5.3), with a range of 17 to 50 years. About the sociodemographic data, the majority of the participants were women, single and without any payed occupation (Table 1). Academically, the mean of the grades is 89.4 (ED 5.7).

Table 2 shows the maximum school level attained by the parents of the participants and stands out among the results that the father school level tends to be higher than the mothers.

\subsection{Precurrent Repertoires and Reading Comprehension Tests}

In the results of the precurrent repertoire tests it was possible to find that the majority of the participants were located in the low levels for precurrents one and two, deferring from the results in precurrent three, where the majority of the sample were located in a high level (Table 3).

Table 1. Sociodemographic description of the sample.

\begin{tabular}{cccc}
\hline Variable & & $\mathrm{n}$ & $\%$ \\
\hline Gender & Female & 104 & 70.7 \\
Male & 43 & 29.3 \\
Marital status & Single & 125 & 85 \\
& Married & 15 & 10.2 \\
& Widow & 1 & 0.7 \\
& Divorce & 2 & 1.4 \\
Payed occupation & Free union & 4 & 2.7 \\
& Yes & 68 & 46.3 \\
\hline
\end{tabular}

$\mathrm{n}=$ frequency, sample $=147$. 
Table 2. School levels attained by parents.

\begin{tabular}{ccccc}
\hline School level & \multicolumn{2}{c}{ Mother } & \multicolumn{2}{c}{ Father } \\
\cline { 2 - 5 } & $\mathrm{n}$ & $\%$ & $\mathrm{n}$ & $\%$ \\
\hline Non & 2 & 1.4 & 16 & 2.0 \\
Elementary school & 25 & 17.0 & 42 & 28.6 \\
Middle school & 48 & 32.7 & 31 & 21.1 \\
High school & 27 & 18.4 & 41 & 27.9 \\
Bachelor's degree & 32 & 21.8 & 14 & 9.5 \\
Masters degree & 10 & 6.8 & -- & -- \\
Other & 3 & 2.0 & &
\end{tabular}

$\mathrm{n}=$ frequency, sample $=147$.

Table 3. Results obtained for the precurrent tests.

\begin{tabular}{ccccccc}
\hline & \multicolumn{2}{c}{ Low } & \multicolumn{2}{c}{ Average } & \multicolumn{2}{c}{ High } \\
\hline Precurrent & $\mathrm{n}$ & $\%$ & $\mathrm{n}$ & $\%$ & $\mathrm{n}$ & $\%$ \\
\hline 1 & 83 & 56.5 & 46 & 31.3 & 18 & 12.2 \\
2 & 69 & 46.9 & 49 & 33.3 & 28 & 19.0 \\
3 & 10 & 6.8 & 54 & 36.7 & 83 & 56.5 \\
\hline
\end{tabular}

$\mathrm{n}=$ frequency, sample $=147$.

For the reading comprehension test, the majority of the participants were located in an average level, although it is important to point out that only two subjects scored in a high level (Table 4).

In Table 5 is presented the distribution of the sample when the results are grouped into approved and non-approved. Standing out that the majority of the participants did not pass this test.

\subsection{Association between the Tests}

A statistical significant association was found between the participants that obtained low scores for the precurrent one and those how approved the reading comprehension test, not like that for the results for precurrents two and three (Table 6).

\section{Discussion}

One of the main results obtained from this research is the significant percentage of participants that did not approved the reading comprehension test, result that concur with the findings of Acuna, Irigoyen, \& Jimenez (2013), who report that in the national and international evaluations preformed to the basic school level students, the scores for the reading comprehension tests tend to be low, making evident the shortcomings that our students have in this educational skill, which, according to the authors, remain present until the higher educational levels, affirmation that can be backup by the results of our 
Table 4. Reading comprehension levels.

\begin{tabular}{ccc}
\hline Level & \multicolumn{2}{c}{ Reading comprehension } \\
\hline Low & $\mathrm{n}$ & $\%$ \\
Average & 35 & 23.8 \\
High & 110 & 74.8 \\
\hline
\end{tabular}

$\mathrm{n}=$ frequency, sample $=147$.

Table 5. Results for the reading comprehension test.

\begin{tabular}{ccc}
\hline Results & Reading comprehension \\
\hline & $\mathrm{n}$ & $\%$ \\
\hline Approved & 34 & 23 \\
Not approved & 113 & 77 \\
\hline
\end{tabular}

$\mathrm{n}=$ frequency, sample $=147$.

Table 6. Association between precurrents and reading comprehension.

\begin{tabular}{ccc}
\hline & $\chi^{2}$ & $\mathrm{P}$ \\
\hline Precurrent 1: word recognition & 4.12 & 0.03 \\
Precurrent 2: phrase recognition & 2.41 & 0.08 \\
Precurrent 3: use of lexicon & 0.02 & 0.50 \\
\hline
\end{tabular}

$\mathrm{n}=$ frequency, sample $=147$.

research, were we found low reading comprehension levels among the college students.

Irigoyen, Jimenez, \& Acuña (2008), point out that the students tend to obtain higher levels in the assignments in which they are required to answer based on information contained in the text or in the question, which corresponds to a situational type adjustment, same type of adjustment needed to answer correctly the precurrent tests used on this research, in which the participants of our study obtained the higher scores compared to the reading comprehension test. Likewise, Irigoyen, Jiménez, \& Acuña (2008), report that the higher level of mistakes in the answers are present in the items that required a substitution type interaction, coinciding with the findings of our research, were the lower scores were obtained in the reading comprehension test.

In the study of Fuentes \& Ribes (2001), it was found that the performance of the subjects is better in the tests of not substitution levels, findings that concur to the results obtained in this research, although, it is important to stand out that in the Fuentes \& Ribes work, different type of text were used, differing from our research, where only a constative text was used.

Fuentes \& Ribes (2006), found a correlation between the levels of lexicon repertoire and the number of correct answers in the reconstructive comprehensive reading test. Based on that statement, it would possible to say that if we perform an evaluation of the 
lexicon repertoires and reading comprehension skills, if we find high levels of lexicon precurrents, we should find high levels of reading comprehension, although, this might not be the case, given that in our results, only an association and not a correlation was found between one component of the lexicon repertoire (word recognition) and the reading comprehension levels. According to this finding, it would be possible to consider that although the subject might have a vast lexicon repertoire, it is not possible to ensure its use for the establishment of reading comprehension skills, inferring that even when the college level students are exposed to high levels of information, this might not be used to get to interact comprehensively with the text.

Other authors, such as Acuña, Irigoyen, \& Jimenez (2013), claim that in the everyday practice of the educational institutions tend to be a preference for expository lessons, situation that generates passive behaviors of listening and information repetition among the students, interactions that develop in the three first psychological functions (contextual, supplementary and selective), in which it is not necessary to have functional conventional properties (Peña-Correal, Ordóñez, Fonseca, \& Fonseca, 2012).

One of the reasons that can explain the results mentioned above, is the type of assignments that the students have to perform in the educational institutions, which do not require to use the functional conventional properties in the stimulating segments to be result, so there are few opportunities to interact in the substitutional referential and not referential functional levels, according to the taxonomy of Ribes \& Lopez (1985), in which is necessary to have functional conventional properties of the stimuli and the involved responses (Peña-Correal, Ordoñez, Fonseca, \& Fonseca, 2012), in these two functional levels is located the reading comprehension skills.

\section{Conclusion}

In summary, the findings of the research showed that the majority of the participants scored low for the precurrent repertories word and phrase recognition, meanwhile, for the third precurrent, corresponding to the use of lexicon, the prevalence was higher for the average level. In the reading comprehension topic, the great majority of the participants did not approved the test.

The association between the precurrent and the reading comprehension tests was analyzed, finding only one statistically significant association between the precurrent one: word recognition, and the reading comprehension.

\section{Research Limitations and Implications}

The study limitations relate to the fact that the results are limited only to the college students from the institutions that participated in the research, being necessary to perform future research that includes students from other college careers, lower school levels, professors and efficient readers, so it could be possible to compare the results obtained. Another limitation of this research is that only one type of text was used for the evaluation of the precurrent repertoires, making important to develop studies that include different type of texts that allows a more comprehensive evaluation. Finally, the 
psychometric characteristics of the test presented are initial, being necessary to develop future controlled research, such as a case-control studies, where could be possible to compare the results obtained by readers with high comprehensive skills against those with low level skills, allowing to evaluate better the psychometric characteristics of the tests used for the data collection of this research.

However, despite its limitations, the study results should be taken into consideration for the development of future research and intervention strategies, being one of the most important the precurrent one, two and comprehension reading low levels obtained and the association between the precurrent one (word recognition) and the reading comprehension.

\section{Acknowledgements}

To the University of Guadalajara and the Secretaria de Educación Jalisco (Jalisco Ministry of Education SEJ) for the facilities provided for the data collection, and to the Consejo Nacional de Ciencia y Tecnología (National Science and Technology Council CONACYT) for the support provided thru a national scholarship for the development of the doctoral dissertation from which this paper is derived. And to the students in the College Institutions, thanking their participation in this research.

\section{Conflict of Interest Declaration}

The authors declare that there is no conflict of interests related with this investigation, the authorship and/or the publication of this paper.

\section{References}

Acuña, K. F., Irigoyen, J. J., \& Jiménez, M. Y. (2013). Understandment of Scientific Contents in College Students. Hermosillo: Qartuppi.

Arroyo, R., Canales, C., Morales, G., Silva, H., \& Carpio, C. (2007). A Research Program for the Functional Analysis of Reading Adjustment. Actacolombiana de Psicología, 10, 31-39.

Fuentes, T. (2005). Precurrent Repertoires of Reconstructive Reading Comprehension. Tesis doctoral. Universidad de Guadalajara.

Fuentes, T. (2007). Academic competence from an interbehavioral perspective. Acta Colombiana de Psicología, 10, 51-58.

Fuentes, T., \& Ribes, E. (2001). A Functional Analysis of Reading Comprehension as a Behavioral Interaction. Revista Latina de Pensamiento y Lenguaje, 9, 181-212.

Fuentes, T., \& Ribes, E. (2006). Influence of Three Preexisting Repertoires on Comprehensive Reading. Revista Mexicana de Psicología, 23, 149-172.

Fuentes, M. (2013). Exclussion: Sign of Highereducation. Excelsior. http://www.excelsior.com.mx/nacional/2013/10/08/922330

Irigoyen, J. J., Acuña, K. F., \& Jiménez, M. Y. (2013). Reading Comprehension and Its Evaluation in the School Context. Revista Mexicana de Investigación en Psicología, 5, 56-70.

Irigoyen, J. J., Jiménez, M. Y., \& Acuña, K. F. (2008). Analysis of Reading Competence in College Students. Boletín Electrónico de Investigación de la Asociación Oaxaqueña de Psicología, 4, 84-96. 
Irigoyen, J. J., Mares, G., Jiménez, M., Rivas, O., Acuña, K., Rocha, H., Noriega, J., \& Rueda, E. (2009). Characterization of Freshmen to the University of Sonora: A Comparative Study. Revista Mexicana de Investigación en Psicología, 1, 71-84.

Kantor, J. R. (1968). AnobjectivePsychology of Gramar. Ohio: The Principia Press, Inc.

Kantor, J. R. (1977). Psychological Linguistics. Chicago: The Principia Press.

Mares, G., Hickman, H., Cabrera, R., Caballero, L., \& Sánchez, E. (2009). Characteristics of the New Admission Psychology Students at the FES Iztacala. In H. Hickman (Coord.), Psicología Iztacala y sus Actores (pp. 189-207). México: UNAM.

Morales-Chávez, G., Hernández-Reyes, M., León, A., Cruz-Alcalá, N., \& Carpio, C. (2010). Effects of Training for the Satisfaction of Congruence Criteria on Reading Adjustment Tasks. Revista Colombiana de Psicología, 19, 11-20.

Organization for Economic Cooperation and Development (1999). Measuring Student Knowledge and Skills: A New Framework for Assessment. Paris: OECD Publishing.

Organization for Economic Cooperation and Development (2003). Education at a Glance: OECD Indicators-2003 Edition. Spanish Translation. https://www.oecd.org/edu/skills-beyond-school/29881539.pdf

Organization for Economic Cooperation and Development (2009). Mexico in Pisa 2009. México D. F.: Instituto Nacional para la Evaluación de la Educación.

Organization for Economic Cooperation and Development (2011). Student's Learning Measurement. Better Practices to Evaluate The School Added, OCDE. Paris: OECD Publishing.

Peña-Correal, T. E., Ordoñez, S., Fonseca, J., \& Fonseca, L. C. (2012). Empiric Research of the Referential Substitutional Function. In M. A. Padilla, \& R. Pérez-Almonacid (Eds.), The Referential Substitutional Function: Critical-Historical Analysis and Perspectives (pp. 35-100). New Orleans: Part of Presses Universitaires Internationales.

Ribes, E. (1990). General Psychology. Mexico: Trillas.

Ribes, E., \& López, F. (1985). Behavioral Theory. Parametric and Field Analysis. D. F.: Trillas.

Secretaría de Educación Pública (2011a). Study Programs 2011. Basic Education. Elementary Education. Sixth Grade. D. F.: Secretaría de Educación Pública.

Secretaria de Educación Pública (2011b). Study Programs 2011. Teacher's Guide. Basic Education. Middle School. Spanish. D. F.: Secretaría de EducaciónPública.

Zarzosa, L., \& Martínez, M. (2011). Reading Comprehension in Mexico and Its Relationship with the Foreign Empirical Research. Revista Mexicana de Psicología Educativa, 2, 15-30. 


\section{Appendix. Item Examples for the Precurrent and Reading Comprehension Tests}

Precurrent Evaluation

Applicator name:

Date:

File:

Part 1: Word recognition

Instruction: Based on the text you just read, match the words from the left column with its definition in the right column by writing in the box the corresponding number. If you do not know the answer you can left it blank.

1. Educative aim

2. Interpersonal interaction
( ) Act characteristic that has a formative character and its shared with specific aims.

( ) Provides information and techniques that facilitate the learning process.

Part 2: Phrase recognition

Instruction: According to the text you just read, now you are going to match every one of the 10 phrases from the left column with the phrase in the right column that states the same, but with other words, by writing in the box the marching number. If you do not know the answer you can left it blank.

1. The trainer is characterized by an innovator attitude, like searching for new teaching and learning possibilities.

2. The teaching strategy is at the content service, because it depends from it to teach. Depends of the economic cost, time and complication contained in that content.
( ) The teaching communication is a key element of the teaching act to get an effective learning.

( ) The content and teaching context characteristics will determine the planification system from the teaching-learning process.

Part 3: Lexicon use

Instruction: Now you are going to complete each of the next phrases, by writing in the line the letter from the matching Word. Pick each word from the box located at the end of the page. If you do not know the answer you can left it blank.

1. The ___ programs, develops and evaluate the contents.

2. Learning depends in a good part from the methods and the so called

\section{Reading Comprehension}

Instruction: Now, we present a text with which we are going to work, read it carefully because later you are going to answer some questions based on its content. You will have an unlimited time to read the text, once you finish, you will proceed to answer questions about its content. 


\section{Didactic ACT}

Marques defines the didactic act as a teacher behavior destine to facilitate the learning in the students. It is a behavior which nature is essentially communicative. The author delimitates the goal of the teaching activities of the learning process as the achievement of specific aims, and specifies as the necessary conditions that the students can and want to perform cognitive operations convenient for that, interacting with the educational resources at its disposal; and that the teacher develops multiple tasks: coordination of the teaching team, resources search, activities with the students, evaluation of the student learning and behavior, tutorial and administrative tasks.

The didactic act reaffirms the teaching communication as the mainstay to develop an effective learning process that determines the ways the individual adapts to the culture in which it is immerse, valuing the communicative skills between teacher-student. It is in the didactic act where the speeches are develop, here the ideas are transform into theories and the dreams become a creative product. So, the speech in the classroom is interested in the social, historic, affective and cultural relationships between the process agents. Beside, promotes that the language and the message locate in the place assigned by the logic and the cotidianity of the pedagogic practice, teacher student relationship and power actions.

\section{Reading Comprehension Evaluation}

Instruction: Once you read the text, answer to each of the following questions, choose the answer option that you consider correct. If you do not know the answer you can left it blank. This time you can consult the text as many times and you need to.

1. The projection of images, slides, transparencies are:

a) Didactic strategies b) Didactic resources c) Didactic act

2. The interleaved questions, the abstracts, the semantic networks, the conceptual maps are:

a) Didactic strategies b) Didactic resources c) Didactic act

3. What are we trying to state in the next example? "I had the luck to have a mother that did not finished elementary school, but had a skill for the oral stories, the popular stories and for the invention of stories, I mean, my mother is capable of doing a onehour story with two characters, and that always marked me".

a) Formal education b) Non formal education c) Informal education 
Submit or recommend next manuscript to SCIRP and we will provide best service for you:

Accepting pre-submission inquiries through Email, Facebook, LinkedIn, Twitter, etc. A wide selection of journals (inclusive of 9 subjects, more than 200 journals)

Providing 24-hour high-quality service

User-friendly online submission system

Fair and swift peer-review system

Efficient typesetting and proofreading procedure

Display of the result of downloads and visits, as well as the number of cited articles

Maximum dissemination of your research work

Submit your manuscript at: http://papersubmission.scirp.org/

Or contact ce@scirp.org 